1

2

3

4

5

6

7

$9 \quad{ }^{4}$ Department of Crop Physiology, Tamil Nadu Agricultural University, Coimbatore, 641 003, India

$10 *$ Corresponding author email: vara@,ksu.edu

\title{
Root length and root lipid composition contribute to drought tolerance of winter and spring wheat
}

\section{Djanaguiraman ${ }^{1,4}$, P.V.V. Prasad ${ }^{1 *}$, J. Kumari $^{2}$ and Z. Rengel $^{3}$}

${ }^{1}$ Department of Agronomy, Kansas State University, Manhattan, Kansas 66502, USA.

${ }^{2}$ National Bureau of Plant Genetic Resources, ICAR, New Delhi 110 012, India

${ }^{3}$ School of Agriculture and Environment, The University of Western Australia (M087), 35 Stirling

8 Highway, Perth WA 6009, Australia 2

4 Keywords Drought, lipid unsaturation, root architecture, maximum root length, spring wheat, 15 winter wheat 
Abstract format for submission

Aim: Mechanisms of drought tolerance based on root architecture and lipid composition in wheat are poorly understood. We quantified the differences in root morphological traits and phospholipid and glycolipid levels between winter and spring wheat genotypes differing in drought tolerance were grown at variable water supply.

Methods: Experiments were conducted using seven winter and four spring wheat (Triticum aestivum) genotypes. In the first experiment, solid agar medium was used to quantify seminal root angles. In the second experiment, the plants were grown in $150-\mathrm{cm}$ columns in a greenhouse under full and deficit moisture supply for 65 days to record root architecture. The root tips (2-cm-long) were used for quantifying polar lipids.

Results: Winter wheat genotypes had $\sim 1.5$ times higher maximum root length than spring wheat ones. Significant differences in the content of root polar lipids, and molecular types and double bond index of galactolipids were observed among spring but not winter wheat genotypes. Drought tolerance of winter wheat genotypes was linked with increased maximum root length. In spring wheat, the attributes such as shallow and well-branched root system and increased unsaturated fatty acid content are linked with drought tolerance.

Conclusion: Winter wheat genotypes had greater maximum root length and total root length compared with spring wheat genotypes; introgression of this trait into spring wheat background can increase the grain yield under drought stress. 


\section{Abstract}

40 Information about mechanisms of drought tolerance based on root architecture and lipid in wheat 41 is scarce. We quantified the differences in root morphological traits and phospholipid and 42 glycolipid levels between winter and spring wheat genotypes and their responses under drought 43 stress conditions. Experiments were conducted using seven winter and four spring wheat (Triticum 44 aestivum) genotypes. In the first experiment, solid agar medium was used to quantify root angle. 45 In the second experiment, the plants were grown in $150-\mathrm{cm}$ columns in a greenhouse under full 46 and deficit moisture content for 65 days for recording root architecture. The bottommost roots 47 were used for quantifying polar lipids. Winter wheat had $\sim 1.5$ times higher maximum root length than spring wheat. Significant differences in contents of root polar lipids, molecular species and double bond index of galactolipids were observed in spring wheat; and no variation was observed in winter wheat. Drought tolerance of winter wheat genotypes was linked with maximum root length. In spring wheat, the attributes like shallow and well branched root system and increased unsaturated fatty acid content are linked with drought tolerance. Winter wheat genotypes had greater maximum root length and total root length compared with spring wheat genotypes and introgression of this trait into spring wheat background can increase the grain yield under drought stress. 


\section{Introduction}

Wheat (Triticum aestivum L.) is an important food crop for more than one third of the world population, and it is sensitive to drought stress, particularly during booting, flowering and grain filling stages (Ihsan et al. 2016). Under rainfed conditions, wheat crop may suffer from drought stress due to unpredictable and infrequent rains, resulting in significant yield losses (Hossain et al. 2012). It is anticipated that the occurrence of drought stress in the major wheat-producing regions will increase in response to changing and variable climate (Reynolds and Ortiz 2010, Semenov and Shewry 2011). In general, breeding efforts to improve crop yields under drought stress are focused on aboveground plant parts (Wachsman et al. 2015), and the knowledge about genotypic differences between winter and spring wheat in root architecture influencing drought tolerance is limited.

Among the various plant organs, roots are severely affected by drought due to their direct contact with drying soil (Yoshimura et al. 2008). The plant capacity to alter the root system architecture (root number, length, positioning and angle) under drought stress has been reported in many crops. Wasson et al. (2012) proposed deep roots, greater root length density, decreased resistance to water movement from soil to root and denser root hairs as the important traits associated with increased uptake of stored soil moisture from the deeper soil horizons. Indeed, well-branched and deeper root systems are often viewed as desirable traits for drought adaptation (Vadez 2014). Modelling studies have indicated that wheat genotypes with deep roots and greater root-length density could significantly improve water absorption under drought stress (Manschadi et al. 2006). In maize, the Steep, Cheap, and Deep (SCD) ideotype was found to be drought tolerant (Zhan et al. 2015), and many features of this ideotype may be relevant to wheat root systems.

Root structure and distribution (root biomass) determine the water extraction pattern from soil (Liu et al. 2004). Research on rice (Oryza sativa L.), chickpea (Cicer arietinum L.), and peanut (Arachis hypogaea L.) indicated that drought tolerance was not associated with deep and profuse rooting systems (Price et al. 2002a, Zaman-Allah et al. 2011a, Ratnakumar and Vadez 2011). However, genotypes with greater root length density and extensive fibrous root system in deeper layers of soil had improved water uptake in sorghum [Sorghum bicolor (L.) Moench; Masi and Maranville 1998], soybean (Glycine max L.; Pantalone et al. 1999) and rice (Price et al. 2002b). In contrast, in wheat the role of greater root length density to grain yield under drought is variable 
86 (Siddique et al. 1990). Some studies found a close relationship between rooting depth, root length density and water extraction pattern in maize and peanut (Hund et al. 2009, Vadez et al. 2013), whereas others showed no such relationship in chickpea and peanut (Zaman-Allah et al. 2011b, Ratnakumar and Vadez 2011). In the field, winter wheat had twice the rooting depth of spring wheat, but only a single genotype of each was tested (Thorup-Kristensen et al. 2009). However, large genetic variability for grain yield was detected in the spring and winter wheat association mapping panel grown under irrigated and dryland conditions; genotypes Gallagher and Jerry 83 were found to be drought-tolerant and -susceptible, respectively (Shroyer 2016). The spring wheat genotype Treasure had increased rooting depth and total root length and ranked high for most of the other root traits (Narayanan and Prasad 2014). Hence, the relevance to drought resistance of different root traits in different winter and spring wheat genotypes remains unknown.

Tolerance to drought stress at the cellular level can be important. Membranes are main targets of degradative processes induced by drought stress (Gigon et al. 2004). Under drought, the membrane lipid content was decreased, correlating with inhibition of lipid synthesis or stimulation of lipolytic activities (Pham Thi et al. 1985, 1987, Matos et al. 2001). However, most studies dealt with the changes in phospho- and glycolipid contents in leaves (Gigon et al. 2004, Pham Thi et al. 1985, 1987), whereas comparable information on root phospho- and glycolipid levels and lipid saturation is scarce.

In this study, we characterized root architecture of selected winter and spring wheat genotypes as well as quantified root phospho- and glycolipid contents under well-watered and drought stress conditions. We hypothesized that drought stress would influence the root architecture and root polar lipid contents in winter and spring wheat genotypes, with variation in these traits potentially associated with drought tolerance.

\section{Materials and Methods}

\section{Materials}

113 Four spring wheat genotypes (Treasure, MT1016, MN081066 and IDO686) and seven winter 114 wheat genotypes (TAM112, TAM111, Yumar, Jerry83, BYRD, CO07W245, and Gallagher) were 115 used for this research. The spring wheat genotypes Treasure and IDO686 were ranked high, and 116 MN08106-6 and MT1016 were ranked low, for most of the root traits (rooting depth, total root 
117 length, total surface area in $0-$ to $30-\mathrm{cm}$ and 30 - to $60-\mathrm{cm}$ soil depths, fine root length, and fine 118 root surface area) in the association panel comprising 250 genotypes (Narayanan and Prasad 2014).

119 In field studies, the winter genotypes Gallagher and TAM111 were found to be drought-tolerant, and BYRD and Jerry83 drought-susceptible (Reddy et al. 2014, Shroyer 2016).

Experimental details

Experiment 1. Genetic variability in coleoptile length, number of seminal roots, seedling root length and root angle

126 Experiment were conducted in complete randomized design with five replications. The seeds of

127 four spring and seven winter wheat genotypes were surface-sterilized using $10 \% \mathrm{v} / \mathrm{v}$ sodium 128 hypochlorite for $5 \mathrm{~min}$ and then washed with deionized water three times. The seeds were 129 germinated in Petri plates using filter paper (Whatman no 42) moistened with $5 \mathrm{~mL}$ of deionized 130 water for $2 \mathrm{~d}$.

131 Sterilized agar (Sigma Type A; $2 \% \mathrm{w} / \mathrm{v})$ was poured into the square Petri plates $(12 \mathrm{x} 12 \mathrm{x}$ $1321.7 \mathrm{~cm}, \mathrm{~L} \times \mathrm{W} \times \mathrm{H}$ ) up to the rim and allowed to solidify. All the sides of Petri plates were sealed 133 using cellophane tape (Staples ${ }^{\circledR}$ Invisible Tape, 2 x $3200 \mathrm{~cm}$, Staples, Manhattan, Kansas). On the $1343^{\text {rd }}$ day, uniformly sized seedling (radicle emerged) were selected and placed one per vertically135 positioned plate with the radicle facing downwards through the cuts in the side of the Petri plates 136 containing agar. The Petri plates were incubated at $25 \pm 1{ }^{\circ} \mathrm{C}$ for $5 \mathrm{~d}$ (Manschadi et al. 2008). After 137 the stipulated time, the root angle of individual root axes of the first and second pair of seminal 138 roots, counting upwards from the primary seminal root (or radicle), was measured at $3 \mathrm{~cm}$ distance 139 from the seed relative to a vertical line passing through the stem base (Manschadi et al. 2006). The 140 angles of the first and second root pairs were averaged. After measuring the root angle, the 141 seedlings were removed from agar, and the coleoptile length, seedling root length and number of 142 seminal roots were measured for each seedling.

144 Experiment 2. Genetic variability for plant height, total dry matter production, root length, root 145 diameter, chlorophyll content, leaf temperature and phospho-glycolipid levels under drought

146 Experiment in factorial design with three replications were conducted To understand the 147 differences in the root system characteristics and phospho- and glycolipid contents among winter 
and spring wheat genotypes, the experiment was conducted in the greenhouse facilities at the Department of Agronomy, Kansas State University, Manhattan, Kansas. Before starting experiments, the greenhouse was fumigated for $1 \mathrm{~h}$ by using an automated sulfur vaporizer (Rosemania, Franklin, TN) to avoid the powdery mildew attack. Plants were grown in polyvinyl chloride (PVC) columns with inside diameter of $7.5 \mathrm{~cm}$ and height of $150 \mathrm{~cm}$. The bottom of the PVC columns had plastic caps with a central hole of $0.5 \mathrm{~cm}$ diameter for drainage. Turface MVP® (PROFILE Products LLC, Buffalo Grove, IL) with bulk density of $577 \pm 32 \mathrm{~kg} \mathrm{~m}^{-3}$ was used as rooting medium. Turface is non-swelling illite and silica clay that allows easy separation of roots. Before sowing, each PVC column was filled with X.Y kg of Turface and fertilized with $4 \mathrm{~g}$ of Osmocote, a slow-release fertilizer with 19:6:12 gravimetric percentages of $\mathrm{N}_{2} \mathrm{P}_{2} \mathrm{O}_{5}: \mathrm{K}_{2} \mathrm{O}$ (Scotts, Marysville, $\mathrm{OH}$ ) and $1 \mathrm{~g}$ of Marathon 1\% G (granular; a.i.: Imidacloprid:1-[(6-chloro-3pyridinyl)methyl]-N-nitro-2-imidazolidinimine; OHP, Inc., Mainland, PA) and evenly mixed with Turface in the top $2 \mathrm{~cm}$.

Two seeds of a single genotype were sown at $4 \mathrm{~cm}$ depth in each PVC column. After emergence, columns were thinned to one plant per column. Plants were irrigated with water (electrical conductivity $0.77 \mathrm{dS} \mathrm{m}^{-1}$ and $\left.\mathrm{pH} \sim 8\right)$ daily at 06:00 (300 mL), 12:00 (300 mL) and 18:00 $\mathrm{h}(300 \mathrm{~mL})$ through an automated drip irrigation system. The drainage from the drip tubes was examined on alternate days to adjust water delivery. Plants were maintained at $24 / 14{ }^{\circ} \mathrm{C}$ (daytime maximum/night time minimum temperature) from sowing to harvest ( $65 \mathrm{~d}$ after sowing) at a photoperiod of $16 \mathrm{~h}$ (natural light and supplemental fluorescent lights). The fungicide, Bumper 41.8 EC (emulsifiable concentrate; a.i.: Propiconazole: 1-[[2-(2,4 dichlorophenyl)-4-propyl-1,3dioxolan-2-yl]methyl]-1H-1,2,4-triazole; $1.2 \mathrm{~mL} \mathrm{~L}^{-1}$; Makhteshim Agan of North America, Inc., Raleigh, NC) was applied $20 \mathrm{~d}$ after sowing to prevent powdery mildew attack.

\section{Drought stress imposition}

The control plants were maintained at $100 \%$ field capacity by irrigation from sowing to final harvest. For the drought treatment, plants were stressed by withholding water from day 5 to final harvest (65 days after sowing). The spring wheat at harvest was in booting stage (Feeks 10) and the winter wheat was at two node visible stage (Feeks 7.0). During the drought stress period, all genotypes showed leaf rolling symptom from 45 days after sowing onwards. 
179

180

181

182

183

184

185

186

187

188

189

190

191

192

193

194

195

196

197

198

199

200

201

202

203

204

205

206

207

208

209

Measurements

Plant height, maximum root length, total root length and root diameter

Plant height was measured one day before the harvest, as the distance from Turface level to the ligule of the youngest leaf. At harvest, the PVC columns were gently inverted at about $140^{\circ}$ to let the content (Turface and plants with entire root system) of columns slip out. The roots were carefully separated from Turface without any breakage in the root system. The shoots were cut at the base; the roots were laid on a flat surface and straightened to measure the maximum root length (from base of the stem to the tip of the root system). The root system was carefully washed in water to remove any adhering Turface, placed between the moist paper towels, sealed in Ziploc bags (S.C. Johnson \& Sons, Inc. Racine, WI), transported to the laboratory, and stored at $4{ }^{\circ} \mathrm{C}$.

The root system of each plant was sliced into 30-cm-long portions; each portion was submerged in water in a tray $(20 \times 15 \times 2 \mathrm{~cm} ; \mathrm{L} \times \mathrm{W} \times \mathrm{H})$ and carefully spread to minimize root overlaps, and was scanned using an Epson photo scanner (Epson Perfection V700 with 6400 dpi resolution, Epson, Long Beach, CA). Images of scanned roots were analyzed using WinRHIZO Pro image system (Regent Instruments, Inc., Quebec City, QC, Canada) to estimate root length and root diameter as explained by McPhee (2005), Singh et al. (2011) and Narayanan and Prasad (2014). The shoots were dried in an oven at $60{ }^{\circ} \mathrm{C}$ for $7 \mathrm{~d}$ for determining dry weight. Root length:shoot length ratio for each genotype was calculated as the ratio of maximum root length to plant height (Tomar et al. 2016).

\section{Chlorophyll index and leaf temperature}

Leaf chlorophyll index and leaf temperature were measured at 5, 10 and 15 days after the appearance of the leaf rolling symptom on the fully expanded topmost leaf. Chlorophyll index was measured using a self-calibrating soil plant analysis development (SPAD) chlorophyll meter (Spectrum Technologies, Plainfield, IL). Leaf temperature was measured using FLIR BCAM SD thermal imaging camera (FLIR Systems Inc., Wilsonville, OR). Chlorophyll index data and leaf temperature were taken three times from the middle portion of the fully expanded topmost leaf, and the readings were averaged.

Electrospray ionization with tandem mass spectrometry (ESI-MS/MS) lipid profiling in root tips 
210 At harvest, bottom roots ( $\sim 2$-cm-long and $\sim 0.5 \mathrm{~g}$ in weight) were collected, chopped into pieces 211 and transferred to a 50-mL glass tube with a Teflon-lined screw cap (Thermo Fisher Scientific, 212 Inc., Waltham, MA, USA) containing $6 \mathrm{~mL}$ of hot isopropanol containing $0.01 \% \mathrm{v} / \mathrm{v}$ butylated 213 hydroxytoluene (BHT) maintained in dry bath $\left(75^{\circ} \mathrm{C}\right.$; Dry bath incubator, Thermo Fisher 214 Scientific Inc., Waltham, MA, USA) for $15 \mathrm{~min}$ to deactivate lipid-hydrolyzing enzymes. After 215 cooling the samples to room temperature, $3 \mathrm{~mL}$ of chloroform and $1.2 \mathrm{~mL}$ of deionized water were 216 added, and samples were stored at $-80^{\circ} \mathrm{C}$ until analysis.

217 The lipid extraction procedure described by Vu et al. (2012) was followed. Briefly, lipids 218 were extracted in isopropanol, BHT, chloroform, and water by shaking on an orbital shaker at 219 room temperature for $1 \mathrm{~h}$ and transferred to a new glass tube using a Pasteur pipette, leaving the 220 root pieces in the original tube. An aliquot of $4 \mathrm{~mL}$ of chloroform:methanol (2:1) was added to the 221 root pieces, the samples were shaken on an orbital shaker at room temperature overnight, and the 222 solvent was combined with the first extract. The addition of extractant, shaking, and transfer steps 223 were performed 4 times. Then, the solvent was evaporated from the extract in an N-EVAP 112 224 nitrogen evaporator (Organomation Associates, Inc., Berlin, MA, USA). Finally, the lipid extract was dissolved in $1 \mathrm{~mL}$ of chloroform and stored at $-80^{\circ} \mathrm{C}$. The extracted root pieces were dried in an oven at $105{ }^{\circ} \mathrm{C}$ overnight, cooled, and weighed to express the lipid content on a dry weight basis. Dry weights were determined using a balance (Mettler Toledo AX, Mettler Toledo International, Inc., Columbus, OH, USA), which had a detection limit of $2 \mu \mathrm{g}$. An automated electrospray ionization-tandem mass spectrometry approach was used to quantify the phosphoand glycolipid contents. Data acquisition and lipid profiling were carried out as described previously (Xiao et al. 2010, Narayanan et al. 2016).

Data analyses

234 Statistical analyses were performed using SAS programs (SAS Institute 2003). The first 235 experiment (genetic variability in coleoptile length, number of seminal roots, seedling root length 236 and root angle) was set in complete randomized design with five replications and the second 237 experiment (genetic variability for plant height, total dry matter production, root length, root 238 diameter, chlorophyll content, leaf temperature and phospho-glycolipid levels under drought) in 239 split-plot design with three replications wherein the main plots were water regimes, and sub-plots were genotypes. Both experiments were repeated twice. Because there was no significant 
241 difference between the two experiments, data were averaged before statistical analyses (Moore and Dixon, 2015). The data for root phospho- and glycolipids were measured in a single experiment.

To assess the overall effect of wheat type (winter and spring), the data from control and drought-stressed winter and spring wheat genotypes were subjected to an analysis of variance with the GLM procedure, and Fisher's least significant difference (LSD) at 5\% significance level was used to test differences between mean values of winter and spring wheat genotypes. The classification of wheat genotypes for drought tolerance was performed using principal component analysis (PCA) as described by Kakani et al. (2005) by considering the percent change over control. Eigenvectors generated by PCA were used to identify parameters that differentiated wheat genotypes for drought tolerance. The factor loading values of variables and genotypes in PC1 and PC2 were used to classify the variables and genotypes.

\section{Results}

1. Genetic variability in coleoptile length, number of seminal roots, seedling root length and root angle (experiment I) Genotypes varied significantly $(P \leq 0.05)$ for coleoptile length, number of seminal roots, seedling root length and root angle (Fig. 1a, b, c, d). Among the winter wheat genotypes, Yumar $(4.0 \mathrm{~cm})$ and CO07W245 $(7.1 \mathrm{~cm})$ had the shortest and longest coleoptile length, respectively (Fig. 1a).

261 Spring wheat genotypes had more seminal roots (4.3) compared to winter wheat genotypes (3.9) 262 (Fig. 1b). The genotypes Gallagher and Jerry 83 had the lowest seedling root length compared with 263 other genotypes (Fig. 1c). Across the genotypes, winter wheat genotypes had wider a root angle $264\left(59^{\circ}\right)$ compared with spring wheat genotypes (57 ; Fig. 1d). Spring wheat genotype MN08106-6 $265\left(46^{\circ}\right)$ and winter wheat genotype CO07W245 $\left(66^{\circ}\right)$ had the narrowest and widest root angles, 266 respectively (Fig. 1d).

2. Genetic variability in plant height, total dry matter production, root length, root diameter, chlorophyll content, leaf temperature and phospho- and glycolipid levels under drought (experiment II) 
273

274

275

276

277

278

279

280

There were significant $(P \leq 0.05)$ effects of genotype, drought and interaction between genotype and drought on plant height and total dry matter production (Fig. 2a, b). Significant $(P \leq 0.05)$ differences between winter and spring wheat genotypes for plant height and total dry matter production were observed. Overall, the spring wheat genotypes were taller $(51 \mathrm{~cm})$ than winter wheat genotypes $(37 \mathrm{~cm})$, and drought stress decreased the plant height of all genotypes except the genotypes BYRD, TAM111and IDO686 (Fig. 2a). Overall, the spring wheat genotypes accumulated less dry matter $\left(0.9\right.$ g plant $\left.^{-1}\right)$ than winter wheat genotypes $\left(1.7\right.$ g plant $\left.^{-1}\right)$ (Fig. $\left.2 b\right)$. Drought stress decreased dry matter accumulation in all the genotypes and maximum decrease was observed in the genotypes BYRD (85\%) followed by TAM112 (77\%).

Maximum root length and root length:shoot length ratio

There were significant $(\mathrm{P} \leq 0.05)$ effects of genotype, drought and interaction between genotype and drought on maximum root length and root length:shoot length ratio (Fig. 3a, b). Maximum root length (cm) was about $\sim 1.5$ times higher, and root length:shoot length ratio 2 times higher, in winter wheat than spring wheat genotypes (Fig. $2 b, d)$. Drought stress significantly $(\mathrm{P} \leq 0.05)$ decreased maximum root length of all winter wheat genotypes except Gallagher and TAM111. Similarly, all the spring wheat genotypes showed a decreased maximum root length except the genotypes IDO686 and MN08106-6 (Fig. 2b). Drought stress increased root length:shoot length ratio in the genotypes Gallagher, TAM111 and Yumar, with no change in the genotypes IDO686 and MN08106-6, whereas the other genotypes showed a decreased root length:shoot length ratio due to drought stress (Fig. 3b).

Total root length and average root diameter

Significant $(P \leq 0.05)$ effects of genotype, drought and interaction between genotype and drought on total root length and average root diameter were observed (Fig. 3a, b). Spring wheat genotypes had lower total root length (by 60\%) and average root diameter (by 9\%) under drought stress compared to winter genotypes (Fig. 4a, b). Drought stress increased the average root diameter of the genotypes BYRD, Jerry83, TAM111 and MT1016 (Fig. 4b). However, the genotype Treasure had decreased root diameter under drought stress (Fig. 4b).

\section{Chlorophyll index and leaf temperature}


303

304

305

306

307

308

309

310

311

312

313

314

315

316

317

318

319

320

321

322

323

324

325

326

327

328

329

330

331

332

333

Significant $(P \leq 0.05)$ differences among the genotypes were observed for leaf temperature and chlorophyll index (Supplementary Fig. 1a, b). The spring wheat genotype IDO686 (40 SPAD units) and winter wheat genotype Jerry83 (34 SPAD units) had the highest and lowest chlorophyll index, respectively (Supplementary Fig. 1a). The winter wheat genotypes had higher leaf temperature (by $0.5^{\circ} \mathrm{C}$ ) than the spring wheat genotype (Supplementary figure $1 \mathrm{~b}$ ).

The phospho- and glycolipid profiles

There were significant $(\mathrm{P} \leq 0.05)$ effects of genotype, drought and interaction between genotype and drought on the molar percentages of MGDG (monogalactosyldiacylglycerol), DGDG (digalactosyldiacylglycerol), PG (phosphatidylglycerol), PC (phosphatidylcholine), PE (phosphatidylethanolamine), and PA (phosphatidic acid) (Fig. 5a, b, c, d, e, f). Spring wheat genotypes had higher glycolipid (total MGDG and DGDG) contents compared to winter wheat genotypes. However, the phospholipids (total PG, PC and PA) were higher in winter wheat than spring wheat genotypes (Fig. 5a, b, c, d, e, f). On average, under drought stress, proportions of MGDG and DGDG in spring wheat genotypes were increased by, respectively, 60 and 96\% relative to control. In contrast, no significant change was observed in winter wheat genotypes (Fig. $5 \mathrm{a}, \mathrm{b})$. Compared with control, the decreases in the proportions of PG, PC and PE due to drought were larger in spring wheat genotypes (38, 30 and 23\%, respectively) than winter wheat genotypes $(5,1$ and $8 \%$, respectively) (Fig. $5 \mathrm{c}, \mathrm{d}, \mathrm{e})$.

Double bond index (DBI)

The double bond index (DBI) of DGDG, MGDG, and PG was significantly ( $\mathrm{P} \leq 0.05)$ decreased by drought stress compared with the control (Fig. 5a, b, c). On average, in spring wheat genotypes drought stress significantly $(\mathrm{P} \leq 0.05)$ increased the $\mathrm{DBI}$ of $\mathrm{PG}, \mathrm{PC}$ and $\mathrm{PE}$, and decreased that of

DGDG and MGDG in comparison with the control. In contrast, in winter wheat genotypes no change in DBI of MGDG, DGDG, PC, PG, PE and PA was caused by drought stress (Fig. 5a, b, $\mathrm{c}, \mathrm{d}, \mathrm{e})$.

\section{Lipid molecular species}

There were significant $(\mathrm{P} \leq 0.05)$ effects of genotype, drought and interaction between genotype and drought on the molar percentages of 34:2, 34:3 and 36:4 molecular species of MGDG and 
334

335

336

337

338

339

340

341

342

DGDG (Fig. 5g, h, i, j, k, 1). All the spring wheat genotypes had increased molar percentages of 34:2, 34:3 and 36:4 MGDG and DGDG under drought stress, whereas varied response was observed in winter wheat. In general there is no much difference between control and drought stress in the levels of above lipid molecular species (Fig. 5g, h, i, j, k, 1).

Significant $(\mathrm{P} \leq 0.05)$ differences were observed in the molar percentages of $34: 2,34: 3,36: 4$ and 36:5 molecular species of phospholipids for genotype, drought and interaction between genotype and drought (Fig. 6a, b, c, d, e, f, g, h, i , j, k, l). In general, the molar percentages of 34:2, 34:3, 36:4 and 36:5 phospholipids were lower in spring wheat compared with winter wheat genotypes.

Principal component analysis (PCA)

The PCA showed that the first two principal components represented $65 \%$ of the variability, with PC1 explaining $45 \%$ of the variance (45\%). Along the PC1, the major contributor to the variance was root length (10\%) followed by very fine root surface area (9\%). In PC2, the major contributors were molar percentages of PG (15\%), MGDG (15\%), and DGDG (15\%) (Fig. 7a). Among the genotypes, the highest variation along PC1 was caused by TAM112 (21\%) followed by Gallagher (14\%), and in PC2 the highest variation was caused by Gallagher (24\%) followed by IDO686 $(21 \%)$ (Fig. $7 b)$. Genotypes that had $+\mathrm{PC} 1$ and $+\mathrm{PC} 2$ scores were classified as tolerant, those with $+\mathrm{PC} 1$ and $-\mathrm{PC} 2$ as moderately tolerant, those with $-\mathrm{PC} 1$ and $+\mathrm{PC} 2$ as moderately susceptible, and those with -PC1 and -PC2 scores as susceptible.

\section{Discussion}

The root architecture can influence the efficiency of water extraction from soil. Irrespective of the water regimes tested, winter wheat genotypes had $\sim 1.5$ times longer maximum root length and 2 times higher root length:shoot length ratio compared to spring wheat genotypes. The deep rooting system of winter wheat compared to spring wheat genotype may be due to its greater root penetration rate ability (Barraclough and Leigh 1984, Kirkegaard and Lilley 2007) and longer duration of the crop (Kirkegaard and Lilley 2007). Deep rooting has been shown to be an important trait under drought stress because it underpins the potential to absorb soil moisture from deeper soil layers (Gowda et al. 2011, Uga et al. 2011, Comas et al. 2013, Vadez 2014). Under drought stress, the tolerant plants tend to develop a deeper root system (high root length:shoot length ratio), 
365

resulting in roots that can reach into still-moist deeper soil layers (Rich and Watt 2013), to avoid the negative effects of drought stress (Manschadi et al. 2006, Kirkegaard et al. 2007). Compared to other genotypes, the winter wheat genotypes, Gallagher and TAM111 had deep rooting system with high total root length under drought (Fig. 3b, 4a). PCA analysis indicated these two genotypes are drought tolerant (Fig. 7b).

The spring wheat genotype Treasure had shallow rooting system but with high total root length compared to other spring wheat genotypes (Fig. 3b, 4a). As proposed by Lynch (2013), reduced lateral root branching in deep soil layers may be an adaptation to drought because it reduces the metabolic cost of soil exploration at depth. Shallow rooting systems, with strong branching, can occupy a greater topsoil volume than deep rooting systems, resulting in enhanced foraging within the topsoil (Valliyodan et al. 2016). Spring wheat is mostly grown in areas where drought is episodic, which makes plant response to rewetting very important for maintaining yield. In this situation, shallow but highly branched root systems would take advantage of rewetting, essentially offering drought tolerance by avoidance (Price et al. 2002a, Sanguineti et al. 2007, Zaman-Allah et al. 2011a, Vadez 2014).

The cell membranes undergo a series of modifications due to drought stress (Repellin et al. 1997). In the present study, drought stress increased the molar percentage of total galactolipids (MGDG and DGDG) in spring wheat genotypes, but no significant changes were observed in winter wheat genotypes (Fig. 5a, b). The total PG and PC levels were decreased by drought stress in spring wheat genotypes, and no variation was observed in winter wheat genotypes (Fig. 5c, d). The increased molar percentages of galactolipids under drought stress in spring wheat genotypes may be due to direct or indirect trafficking of PC or PC-derived lipids to the chloroplast for galactolipid biosynthesis; alternatively, PA may be dephosphorylated to DAG to form galactolipids (Awai et al. 2001, Benning 2009, Kim et al. 2010, Moellering et al. 2010).

Under drought, the MGDG:DGDG ratio of spring wheat genotypes was decreased by $18 \%$, but there was no change in winter wheat genotypes. The MGDG:DGDG ratio is important for maintenance of lamellar bilayer structures (Hincha et al. 1998) because DGDG is a bilayerforming lipid, whereas MGDG has a propensity to form non-lamellar hexagonal structures (Webb and Green 1991). Hence, a decrease in the MGDG:DGDG ratio under drought stress would have decreased the stability of the root-cell plasma membrane in spring wheat genotypes. 
There was no variation in lipid molecular species in winter wheat genotypes (Fig. 5 and 6), but the spring wheat genotypes showed a significant increase in the molar percentages of $34: 2$, 34:3 and 36:4 species of MGDG and DGDG under drought stress (Fig. 5). This could be due to increased concentration of saturated 18:2 fatty acid and deactivation of desaturase under drought stress. The decrease in double bond index value under drought stress in spring wheat genotypes confirms the deactivation of desaturase. The spring wheat genotypes had decreased total PC and increased total MGDG molar percentages under drought stress, indicating altered structure and fluidity of root-cell plasma membrane. Earlier studies showed that the double bond index of phospho- and glycolipids decreased in the drought-sensitive cultivar, whereas it remained unchanged in the drought-tolerant cultivars under drought stress (Repellin et al. 1997).

Root is an important organ involved in drought tolerance. However, in many cases, the degree of root growth did not explain the differences in yield (Pantuwan et al. 2002; Subashri et al. 2009); in that situation the drought tolerance was is mainly dependent on shoot traits. For example, deep or profuse rooting would have no effect in shallow soil and deeper rooting might lead to faster soil water depletion and drought susceptibility. Many studies have indicated the shoot traits such as reduced canopy temperature, stomatal conductance, transpiration and osmotic adjustments play a major role in drought tolerance.

Even though PVC columns filled with Turface cannot replicate the real field situation, Turface ${ }^{\circledR}$ clay may be useful for studying root architecture of major cereals such as wheat, maize and finger millet (Eleusine coracana L. Gaertn) (Goron et al. 2015). Nevertheless, further studies in field to validate drought tolerance of this genotypes will provide more understanding of differential drought tolerance of spring and winter wheat.

\section{Conclusions}

Irrespective of water regimes, maximum root length was $\sim 1.5$ times higher in winter wheat compared to spring wheat genotypes. The double bond index of galactolipids was lower in spring wheat compared to winter wheat genotypes. Drought stress decreased maximum root length, total dry matter accumulation, maximum root length:shoot length ratio, total root length, molar percentage of PC, PE, and PG, and double bond index of DGDG and MGDG. The principal 
424 component analysis separated various wheat genotypes into drought tolerant (winter: TAM111

425 and Gallagher; spring: Treasure) and drought susceptible (winter: BYRD and CO07W245, spring:

426 MT1016) based on all traits. The maximum root length and total root length were higher in winter 427 wheat drought-tolerant genotypes compared to susceptible genotypes. In spring wheat genotype 428 the drought tolerance attributes are shallow root system with profuse branching, increased 429 unsaturated fatty acid contents, MGDG:DGDG ratio, and PG molar percentages. Introgression of 430 drought tolerance traits, particularly maximum root length, from winter wheat to spring wheat 431 background can increase the spring wheat grain yield under drought stress.

\section{Acknowledgements}

433 We thank the Triticeae Coordinated Agricultural Project (Triticeae-CAP), grant no. 2011-68002434 30029, from the USDA NIFA, United States Agency for International Development (USAID) 435 Feed the Future Innovation Lab for Climate Resilient Wheat (Grant no. AID-0AAA-1300008). 436 The lipid analyses described in this work were performed at the Kansas Lipidomics Research 437 Center Analytical Laboratory; instrument acquisition and lipidomics method development was 438 supported by the National Science Foundation (EPS 0236913, MCB 0920663, MCB 1413036, 439 DBI 0521587, DBI 1228622), Kansas Technology Enterprise Corporation, K-IDeA Networks of 440 Biomedical Research Excellence (INBRE) of the National Institute of Health (P20GM103418) 441 and Kansas State University. The senior author (MD) thanks Tamil Nadu Agricultural University, 442 India, for permitting him to perform post-doctoral research at Kansas State University, USA. ZR 443 is supported by Australian Research Council (DP160104434). Mention of trademark or proprietary 444 product does not constitute a guarantee or warranty of the product by Kansas State University and 445 does not imply its approval to the exclusion of other products, which may also be suitable. This 446 publication is Contribution No. XXXXXXXXXX from the Kansas Agricultural Experiment 447 Station. 


\section{References}

Awai K, Marechal E, Block MA, Brun D, Masuda T, Shimada H, Takamiya KI, Ohta H, Joyard J (2001) Two types of MGDG synthase genes, found widely in both 16:3 and 18:3 plants, differentially mediate galactolipid syntheses in photosynthetic and nonphotosynthetic tissues in Arabidopsis thaliana. Proc Natl Acad Sci 98:10960-10965.

Barraclough PB, Leigh RA (1984) The growth and activity of winter-wheat roots in the field-the effect of sowing date and soil type on root-growth of high-yielding crops. J Agri Sci 103: $59-74$.

Benning C (2009) Mechanisms of lipid transport involved in organelle biogenesis in plant cells. Annu Rev Cell Dev Biol 25:71-91.

Comas LH, Becker SR, Cruz VMV, Byrne PF, Dierig DA (2013) Root traits contributing to plant productivity under drought. Front Plant Sci 4:442.

Gigon A, Matos A, Laffray D, Zuily-fodil Y, Pham-Thi A (2004) Effect of drought stress on lipid metabolism in the leaves of Arabidopsis thaliana (Ecotype Columbia), Ann Bot 94: 345-351.

Goron TL, Watts S, Shearer CR, Raizada MN (2015) Growth in Turface clay permits root hair phenotyping along the entire crown root in cereal crops and demonstrates that root hair growth can extend well beyond the root hair zone. BMC Res Notes 5:8-143.

Gowda VRP, Henry A, Yamauchi A, Shashidhar HE, Serraj R (2011) Root biology and genetic improvement for drought avoidance in rice. Field Crops Res 122:1-13.

Hincha DK, Oliver AE, Crowe JH (1998) The effects of chloroplast lipids on the stability of liposomes during freezing and drying. Biochim Biophys Acta 1368:150-160.

Hossain A, Teixeira da Silva JA, Lozovskaya MV, Zvolinsky VP (2012) High temperature combined with drought affect rainfed spring wheat and barley in South-Eastern Russia: I. Phenology and growth. Saudi J Biol Sci 19:473-487.

Hund A, Ruta N, Liedgens M (2009) Rooting depth and water use efficiency of tropical maize inbred lines, differing in drought tolerance. Plant Soil 318:311-325.

Ihsan M, El-Nakhlawy FS, Ismail SM, Fahad S, Daur I (2016) Wheat phenological development and growth studies as affected by drought and late season high temperature stress under arid environment. Front Plant Sci 7:795.

Kakani VG, Reddy KR, Koti S, Wallace TP, Prasad PVV, Reddy VR, Zhao D (2005) Differences in in-vitro pollen germination and pollen tube growth of cotton cultivars in response to high temperature. Ann Bot 96:59-67.

Kim KU, Vijayan P, Carlsson AS, Barkan L, Browse J (2010) A mutation in the LPAT1 gene suppresses the sensitivity of fab1 plants to low temperature. Plant Physiol 153:1135-1143. 
Kirkegaard JA, Lilley JM (2007) Root penetration rate-a benchmark to identify soil and plant limitations to rooting depth in wheat. Aust J Exp Agric 47:590-602.

Kirkegaard JA, Lilley JM, Howe GN, Graham JM (2007) Impact of subsoil water use on wheat yield. Aust J Agric Res 58:303-315.

Liu HS, Li FM, Xu H (2004) Deficiency of water can enhance root respiration rate of droughtsensitive but not drought-tolerant spring wheat. Agr Water Manage 64:41-48.

Lynch JP (2013) Steep, cheap and deep: an ideotype to optimize water and N acquisition by maize root systems. Ann Bot 112:347-357.

Manschadi AM, Christopher J, DeVoil P, Hammer GL (2006) The role of root architectural traits in adaptation of wheat to water-limited environments. Funct Plant Biol 33:823-837.

Manschadi AM, Hammer GL, Christopher JT, de Voil P (2008) Genotypic variation in seedling root architectural traits and implications for drought adaptation in wheat (Triticum aestivum L.). Plant Soil 303:115-129.

Masi CEA, Maranville JW (1998) Evaluation of sorghum root branching using fractals. J Agr Sci (Cambridge) 131:259-265.

Matos AR, d'Arcy-Lameta A, Franca M, Petres S, Edelman L, Kader J, Zuily-Fodil Y, Pham-Thi AT (2001) A novel patatin-like gene stimulated by drought stress encodes a galactolipid acyl hydrolase. FEBS Lett 491:188-192.

McPhee K (2005) Variation for seedling root architecture in the core collection of pea germplasm. Crop Sci 45:1758-1763.

Moellering ER, Muthan B, Benning C (2010) Freezing tolerance in plants requires lipid remodeling at the outer chloroplast membrane. Science 330:226-228.

Moore KJ, Dixon PM (2015) Analysis of combined experiments revisited. Agron J 107:763-771.

Narayanan S, Prasad PVV (2014) Characterization of a spring wheat association mapping panel for root traits. Agronomy J 106:1593-1604.

Narayanan S, Tamura PJ, Roth MR, Prasad PV, Welti R (2016) Wheat leaf lipids during heat stress: I. High day and night temperatures result in major lipid alterations. Plant Cell Environ 39:787-803.

Pantalone VR, Rebetzke GJ, Burton JW, Carter TE, Israel DW (1999) Soybean PI 416937 root system contributes to biomass accumulation in reciprocal grafts. Agronomy J 91:840-844.

Pantuwan G, Fukai S, Cooper M, Rajatasereekul S, O'Toole JC (2002) Yield response of rice (Oryza sativa L) genotypes to different types of drought under rainfed lowlands - Part 3. Plant factors contributing to drought resistance. Field Crops Res. 73:181-200. 
Pham-Thi AT, Borrel-Flood C, Vieira da Silva J, Justin AM, Mazliak P (1985) Effects of water stress on lipid metabolism in cotton leaves. Phytochemistry 24:723-727.

Pham-Thi AT, Borrel-Flood C, Vieira da Silva J, Justin AM, Mazliak P (1987) Effects of drought on [1-14C]-oleic and [1-14C]-linoleic acid desaturation in cotton leaves. Physiol Plant 69:147-150.

Price AH, Cairns JE, Horton P, Jones HG, Griffiths H (2002a) Linking drought-resistance mechanisms to drought avoidance in upland rice using a QTL approach: progress and new opportunities to integrate stomatal and mesophyll responses. J Exp Bot 53:989-1004.

Price AH, Townend J, Jones MP, Audebert A, Courtois B (2002b) Mapping QTLs associated with drought avoidance in upland rice grown in the Philippines and West Africa. Plant Mol Biol $48,683-695$.

Ratnakumar P, Vadez V (2011) Groundnut (Arachis hypogaea) genotypes tolerant to intermittent drought maintain a high harvest index and have small leaf canopy under stress. Funct Plant Biol 38:1016-1023.

Reddy SK, Liu S, Rudd JC, Xue Q, Payton P, Finlayson SA, Mahan J, Akhunova A, Holalu SV, Lu N (2014) Physiology and transcriptomics of water deficit stress responses in wheat cultivars TAM 111 and TAM 112. J Plant Physiol 171:1289-1298.

Repellin A, Pham-Thi AT, Tashakorie A, Sahsah Y, Daniel C, Zuily-Fodil Y (1997) Leaf membrane lipids and drought tolerance in young coconut palms (Cocos nucifera $\mathrm{L}$.). Eur J Agron 6:25-33.

Reynolds MP, Ortiz R (2010) Adapting crops to climate change: a summary. In: Reynolds MP (eds) Climate change and crop production, CAB international, pp 1-8.

Rich SM, Watt M (2013) Soil conditions and cereal root system architecture: review and considerations for linking Darwin and Weaver. J Exp Bot 64:1193-1208.

Sanguineti MC, Li S, Maccaferri M, Corneti S, Rotondo F, Chiari T, Tuberosa R (2007) Genetic dissection of seminal root architecture in elite durum wheat germplasm. Ann Appl Biol 151:291-305.

SAS Institute (2003) SAS Users Guide. Version 9.1. SAS Institute, Cary, NC

Semenov MA, Shewry PR (2011) Modelling predicts that heat stress and not drought will limit wheat yield in Europe. Sci Rep 1:1-5.

Shroyer KJ (2016) The effects of drought and high temperature stress on reproduction, physiology, and yield of spring and winter wheat. Ph. D thesis submitted to Department of Agronomy, Kansas State University, Manhattan, Kansas 66502.

Siddique KHM, Belford RK, Tennant D (1990) Root:shoot ratios of old and modern, tall and semidwarf wheats in a Mediterranean environment. Plant Soil 121:89-98. 
Singh V, van Oosterom EJ, Jordan DR, Hunt CH, Hammer GL (2011) Genetic variability and control of nodal root angle in sorghum. Crop Sci 51:2011-2020.

Subashri M, Robin S, Vinod KK, Rajeswari S, Mohanasundaram K, Raveendran TS (2009) Trait identification and QTL validation for reproductive stage drought resistance in rice using selective genotyping of near flowering RILs. Euphytica 166: 291-305.

Thorup-Kristensen K, Salmeron Cortasa M, Loges R (2009) Winter wheat roots grow twice as deep as spring wheat roots, is this important for $\mathrm{N}$ uptake and $\mathrm{N}$ leaching losses? Plant Soil 322:101-114.

Tomar RSS, Tiwari S, Vinod, Naik BK, Chand S, Deshmukh R, et al. (2016) Molecular and morpho-agronomical characterization of root architecture at seedling and reproductive stages for drought tolerance in wheat. PLoS ONE 11(6): e0156528.

Uga Y, Okuno K, Yano M (2011) Dro1, a major QTL involved in deep rooting of rice under upland field conditions. J Exp Bot 62:2485-2494.

Vadez V (2014) Root hydraulics: The forgotten side of roots in drought adaptation. Field Crop Res 165:15-24.

Vadez V, Rao JS, Bhatnagar-Mathur P, Sharma KK (2013) DREB1A promotes root development in deep soil layers and increases water extraction under water stress in groundnut. Plant Biol 15:45-52.

Valliyodan B, Ye H, Song L, Murphy M, Shannon JG, Nguyen HT (2016) Genetic diversity and genomic strategies for improving drought and waterlogging tolerance in soybeans. J Exp Bot erw433. doi: 10.1093/jxb/erw433

Vu HS, Tamura P, Galeva NA, Chaturvedi R, Roth MR, Williams TD, Wang X, Shah J, Welti R (2012) Direct infusion mass spectrometry of oxylipin-containing Arabidopsis membrane lipids reveals varied patterns in different stress responses. Plant Physiol 158:324-339.

Wachsman G, Sparks EE, Benfey PN (2015) Genes and networks regulating root anatomy and architecture. New Phytol 208:26-38.

Wasson AP, Richards RA, Chatrath R, Misra SC, Prasad SV, Rebetzke GJ, Kirkegaard JA, Christopher J, Watt M (2012) Traits and selection strategies to improve root systems and water uptake in water-limited wheat crops. J Exp Bot 63:3485-3498.

Webb MS, Green BR (1991) Biochemical and physical properties of thylacoid acyl lipids. Biochim Biophys Acta 1060:133-158.

Xiao S, Gao W, Chen QF, Chan SW, Zheng SX, Ma J, Wang M, Welti R, Chye ML (2010) Overexpression of Arabidopsis acyl-CoA binding protein ACBP3 promotes starvationinduced and age-dependent leaf senescence. Plant Cell 22:1463-1482. 
Yoshimura K, Masuda A, Kuwano M, Yokota A, Akashi K (2008) Programmed proteome response for drought avoidance/tolerance in the root of a $\mathrm{C}_{3}$ xerophyte (wild watermelon) under water deficits. Plant Cell Physiol 49:226-241.

Zaman-Allah M, Jenkinson DM, Vadez V (2011a) Chickpea genotypes contrasting for seed yield under terminal drought stress in the field differ for traits related to the control of water use. Funct Plant Biol 38:270-281.

Zaman-Allah M, Jenkinson DM, Vadez V (2011b) A conservative pattern of water use, rather than deep or profuse rooting, is critical for the terminal drought tolerance of chickpea. J Exp Bot 62:4239-4252.

Zhan A, Schneider H, Lynch JP (2015) Reduced lateral root branching density improves drought tolerance in maize. Plant Physiol 168:1603-1615. 
598

599

600

601

602

603

604

605

606

607

608

609

610

611

612

613

614

615

616

617

618

619

620

621

622

623

624

625

\section{Figure legends}

Fig. 1. Genetic variability in (a) coleoptile length, (b) number of seminal roots, (c) root length, and (d) root angle among winter and spring wheat genotypes (experiment I). Vertical bars denote \pm S.E. Means with different letters were significantly different at $P \leq 0.05$ level.

Fig. 2. Interaction effect of drought and genotype on (a) plant height (cm) and (b) total dry matter production $\left(\mathrm{g} \mathrm{plant}^{-1}\right.$ ) among winter and spring wheat genotypes (experiment II). Vertical bars denote \pm S.E. The control and drought treatments of each genotype were compared for significance at $P \leq 0.05$ level, and the means with different letters were significantly different.

Fig. 3. Interaction effect of drought and genotype on (a) maximum root length $(\mathrm{cm})(\mathrm{b})$ maximum root length:shoot length ratio among winter and spring wheat genotypes (experiment II). Vertical bars denote \pm S.E. The control and drought treatments of each genotype were compared for significance at $P \leq 0.05$ level, and the means with different letters were significantly different.

Fig. 4. Interaction effect of drought and genotype on (a) total root length (cm) and (b) average root diameter ( $\mathrm{mm}$ ) among winter and spring wheat genotypes (experiment II). Vertical bars denote \pm S.E. The control and drought treatments of each genotype were compared for significance at $P \leq 0.05$ level, and the means with different letters were significantly different.

Fig. 5. Interaction effect of drought and genotype on (a) total monogalactosyldiacylglycerol (MGDG), (b) total digalactosyldiacylglycerol (DGDG), (c) total phosphatidylglycerol (PG), (d) total phosphatidylcholine (PC), (e) total phosphatidylethanolamine (PE), (f) total phosphatidic acid (PA), (g), (h), (i), (j), (k) and (1) 34:2, 34:3 and 36:4 MGDG and DGDG molecular species (mol\%) (experiment II). Values shown are \pm S.E. The control and drought treatments of each genotype were compared for significance at $P \leq 0.05$ level, and the means with different letters were significantly different.

Fig. 6. Interaction effect of drought and genotype on lipid molecular species (a) 34:2 PC, (b) 34:2 PG, (c) 34:2 PE, (d) 34:3 PC, (e) 34:3 PE, (f) 34:3 PA, (g) 36:4 PE, (h) 36:4 PG, (i) 36:4 PI, (j) 36:5 PC, (k) 36:5 PE, and (1) 36:5 PA (mol\%) (experiment II). Values shown are \pm S.E. The control and drought treatments of each genotype were compared for significance at $P \leq 0.05$ level, and the means with different letters were significantly different. 
626 Fig. 7. First and second principal component scores (PC1 and PC2) for identifying traits conferring

627 drought tolerance: (a) the factor loading values for variables were indicated by thick lines radiating 628 from the center showing the direction (angle) and magnitude (length), and (b) classification of 629 eleven wheat genotypes based on the factor scores of first and second principal components 630 (experiment II). Legend for (a): 1, total dry matter production ( $\mathrm{g}$ plant $\left.{ }^{-1}\right)$; 2 , maximum root length $631(\mathrm{~cm}) ; 3$, root:shoot ratio; 4, total root length $(\mathrm{cm}) ; 5$, surface area $\left(\mathrm{cm}^{2}\right) ; 6$, root diameter $(\mathrm{mm}) ; 7$, 632 root volume $\left(\mathrm{cm}^{3}\right) ; 8$, length of very fine roots $(\mathrm{cm}) ; 9$, surface area of very fine root $\left(\mathrm{cm}^{2}\right) ; 10$, 633 volume of very fine root $\left(\mathrm{cm}^{3}\right) ; 11$, monogalactosyldiacylglycerol (mol\%); 12 , 634 digalactosyldiacylglycerol (mol\%); 13, phosphatidylglycerol (mol\%); 14, phosphatidic acid 635 (mol\%); 15, phosphatidylethanolamine (mol\%); 16, phosphatidylcholine (mol\%); 17, surface area 636 of fine root $\left(\mathrm{cm}^{2}\right) ; 18$, volume of fine $\operatorname{root}\left(\mathrm{cm}^{3}\right) ; 19$, root length of fine $\operatorname{root}(\mathrm{cm})$; 20, plant height $637(\mathrm{~cm})$.

638 Supplementary Fig. 1. Main effect of genotype (winter and spring wheat) on (a) chlorophyll index 639 (SPAD units) and (b) leaf temperature $\left({ }^{\circ} \mathrm{C}\right)$ (experiment II). Vertical bars denote \pm S.E. Means 640 with different letters were significantly different. 
Fig. 1.

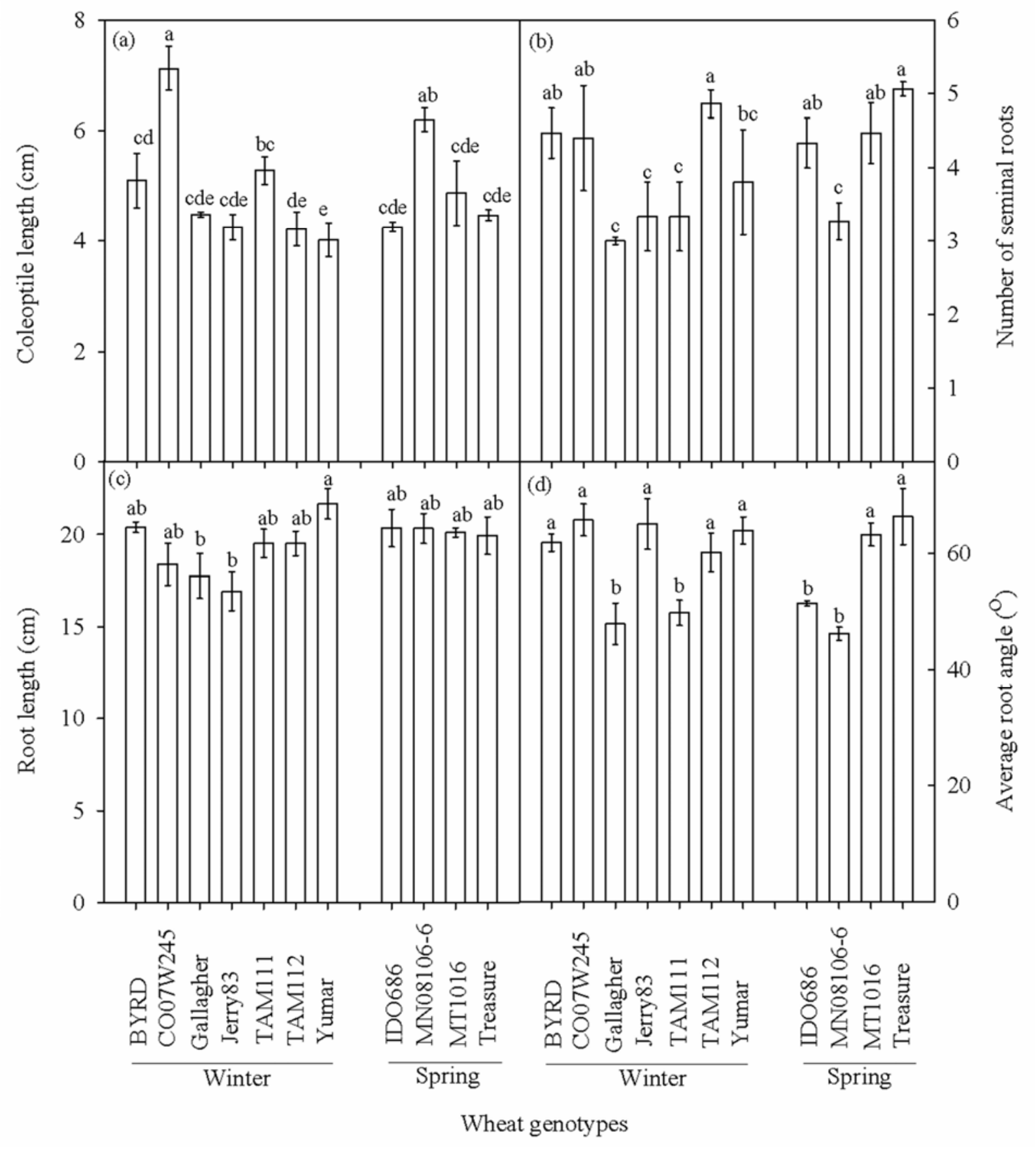


Fig. 2.

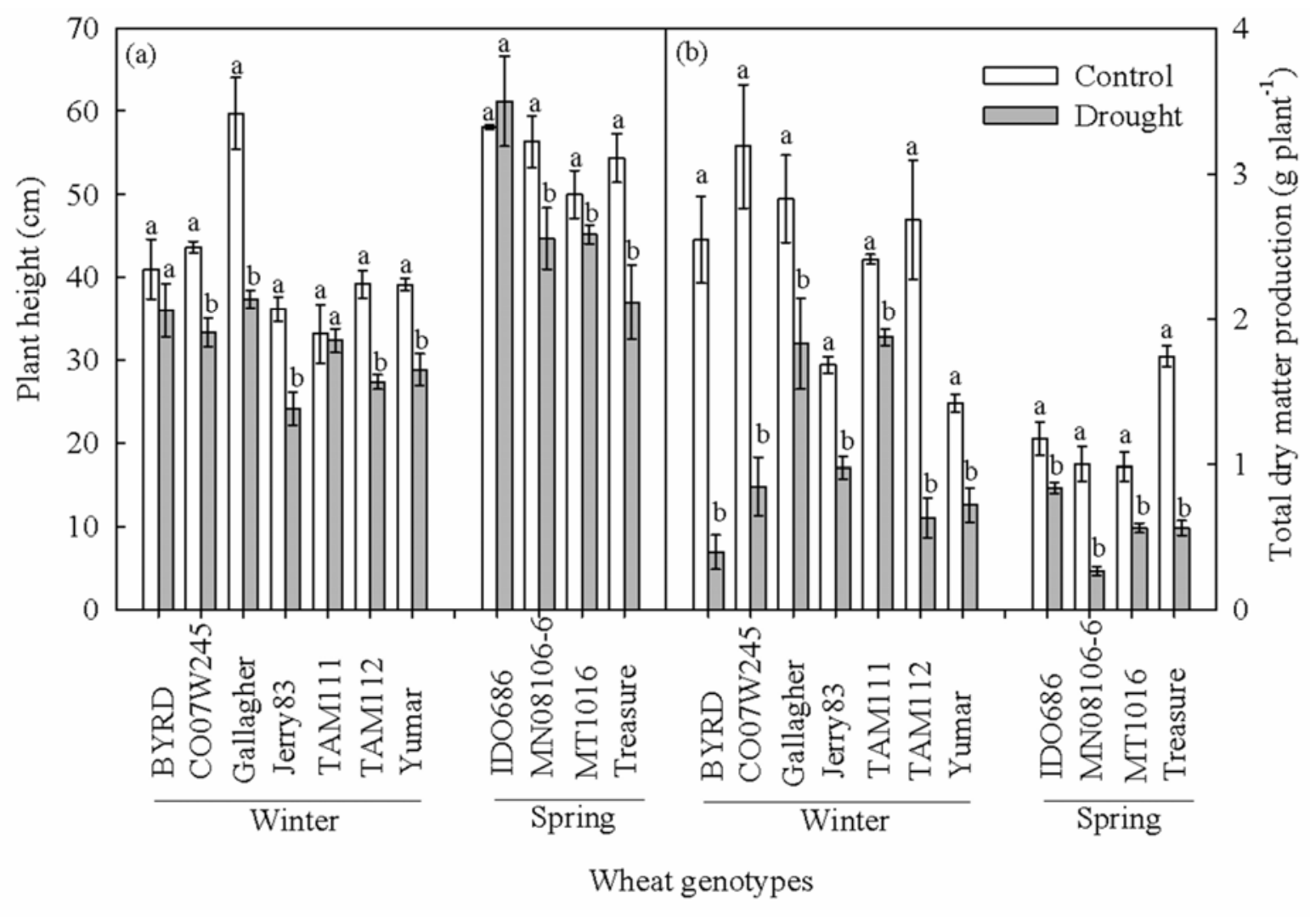


$645 \quad$ Fig. 3.

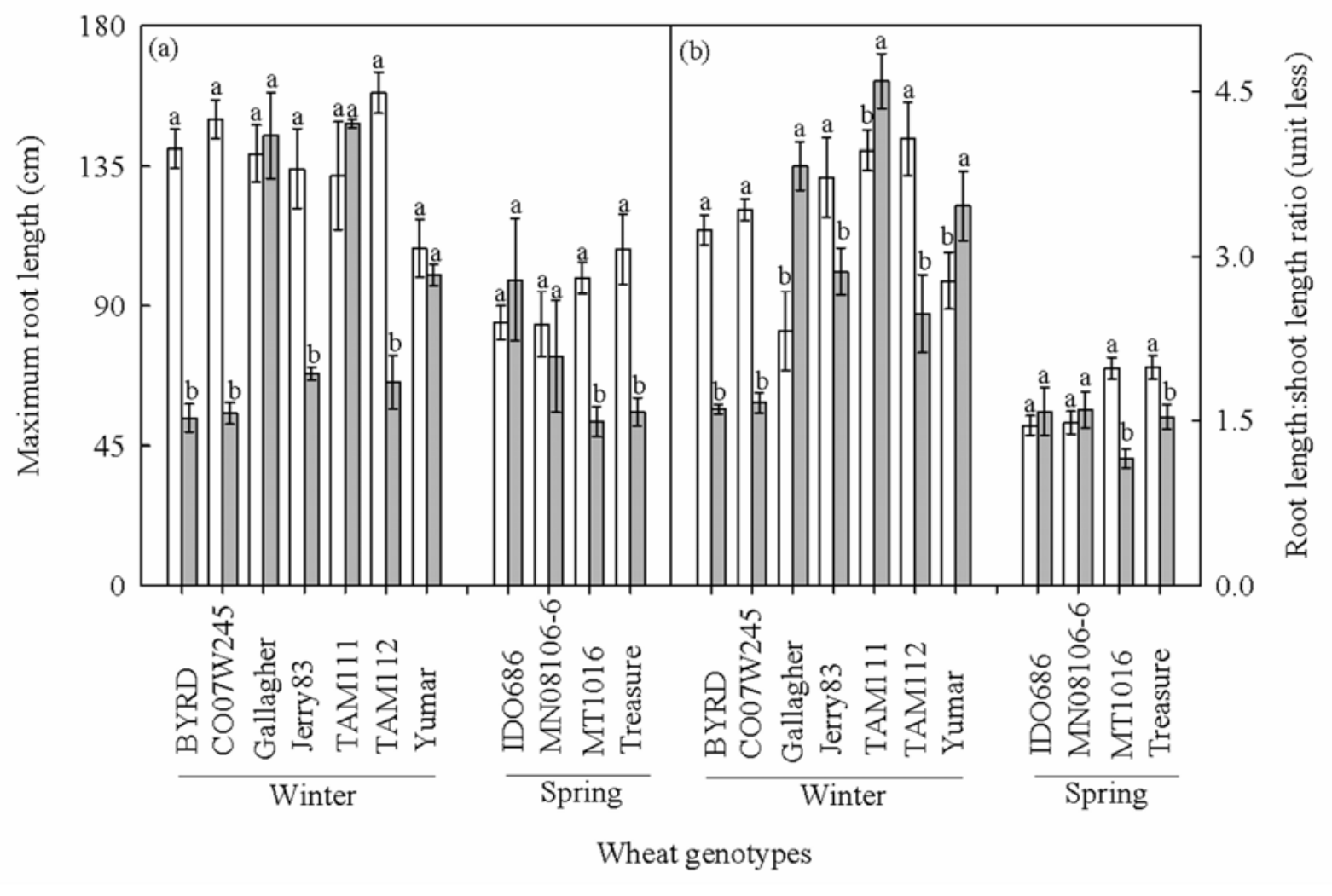

646 
Fig. 4.

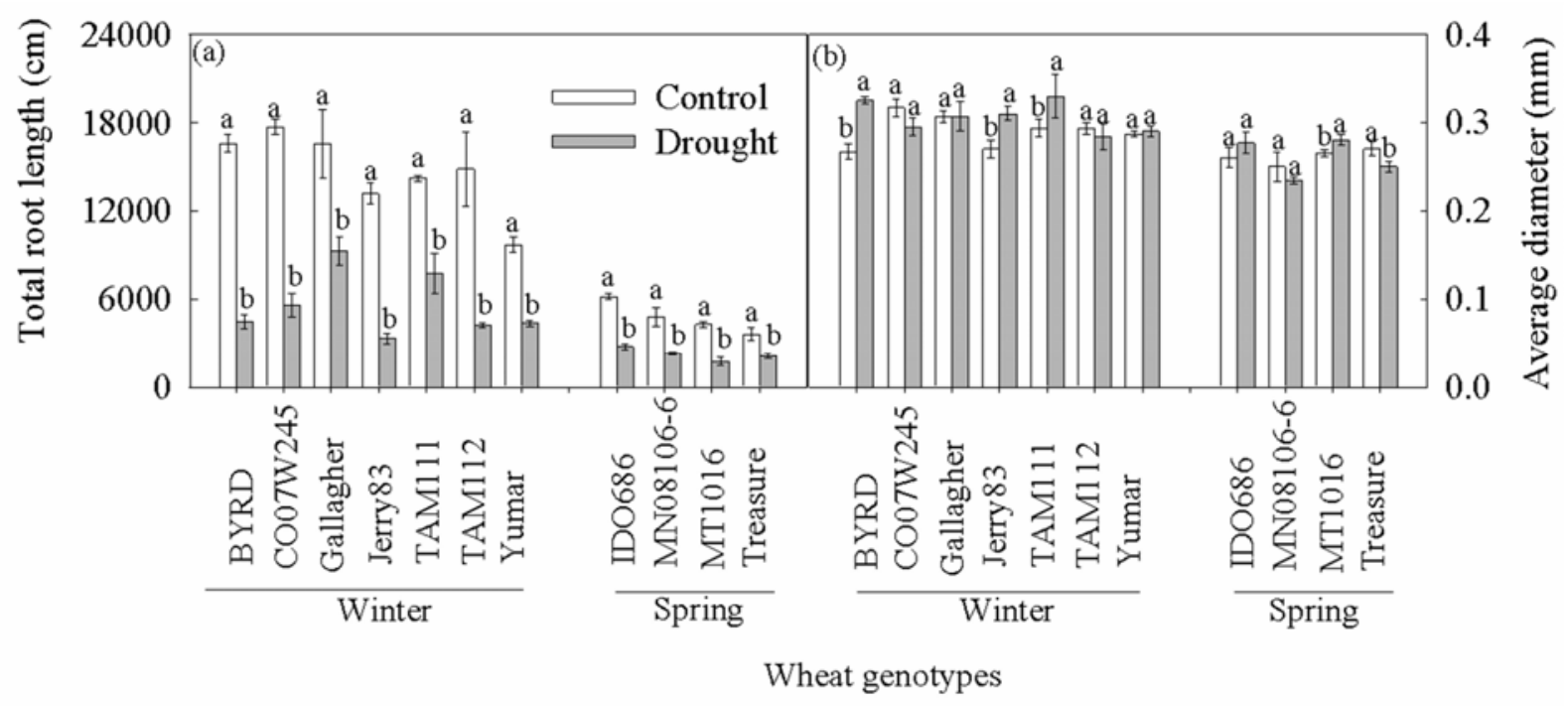


Fig. 5.

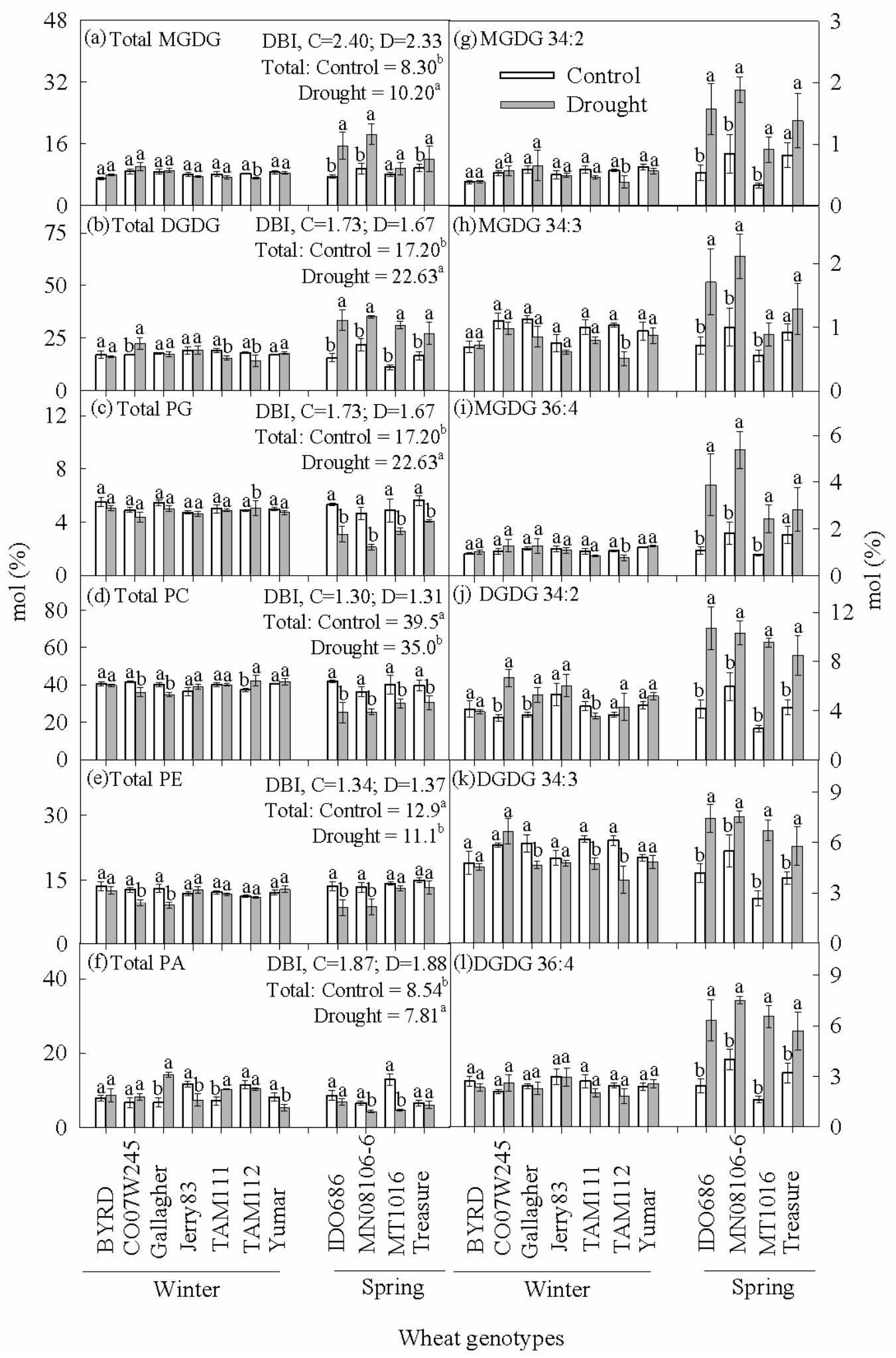


Fig. 6.

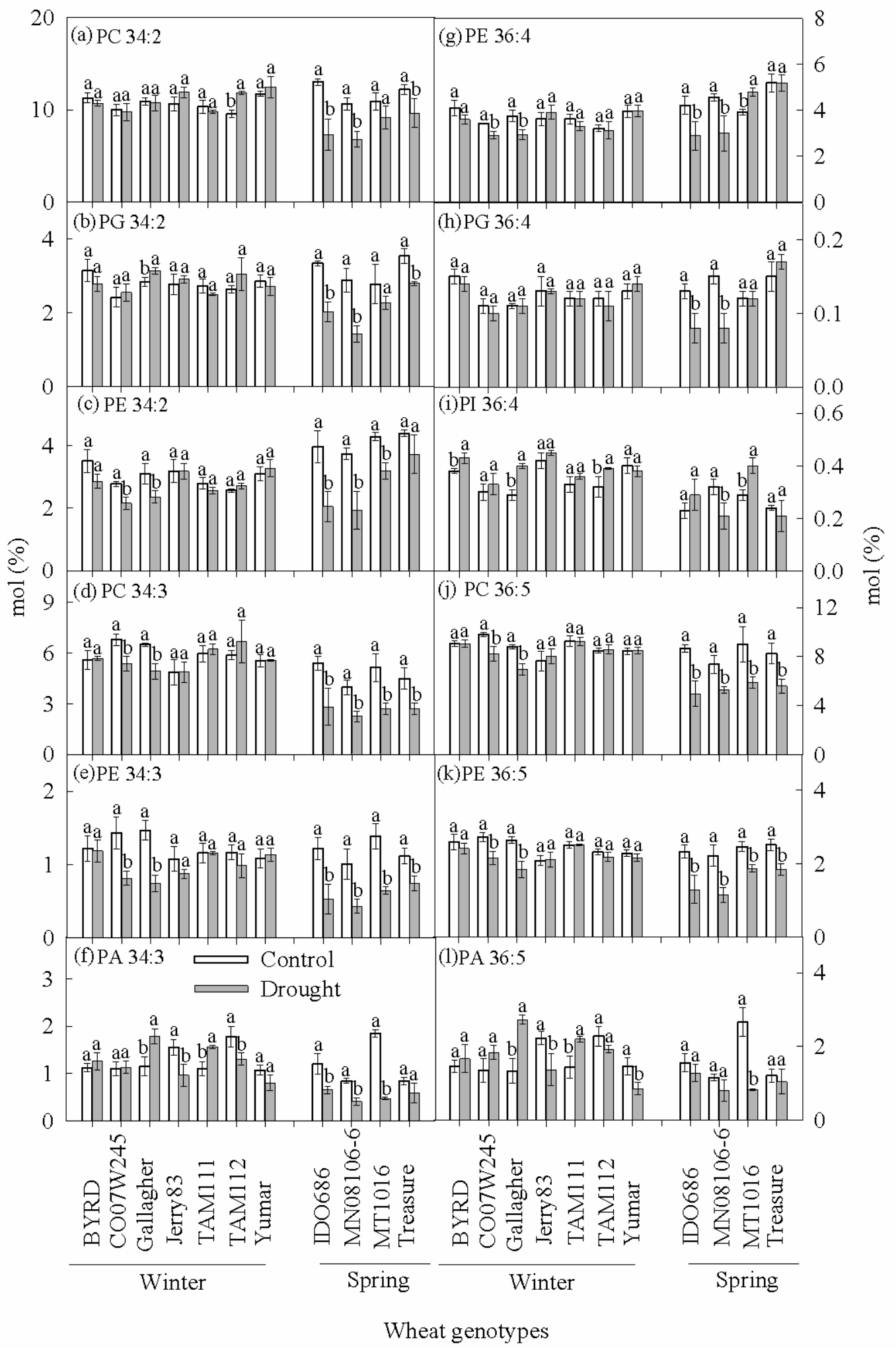


653 Fig. 7.

(a) Traits (PC1 and PC2: $65.41 \%$ )

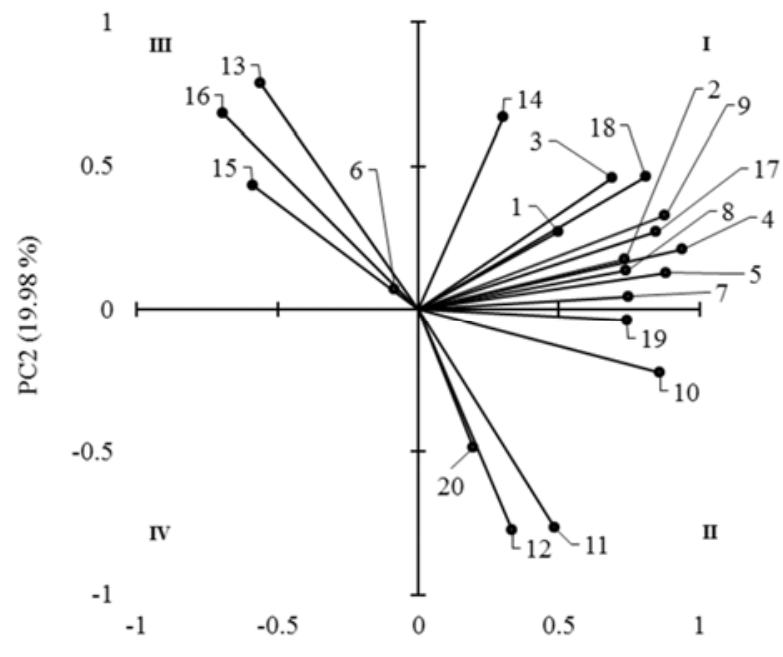

PC1 (45.43\%) (b) Genotypes (PC1 and PC2: $65.41 \%$ )

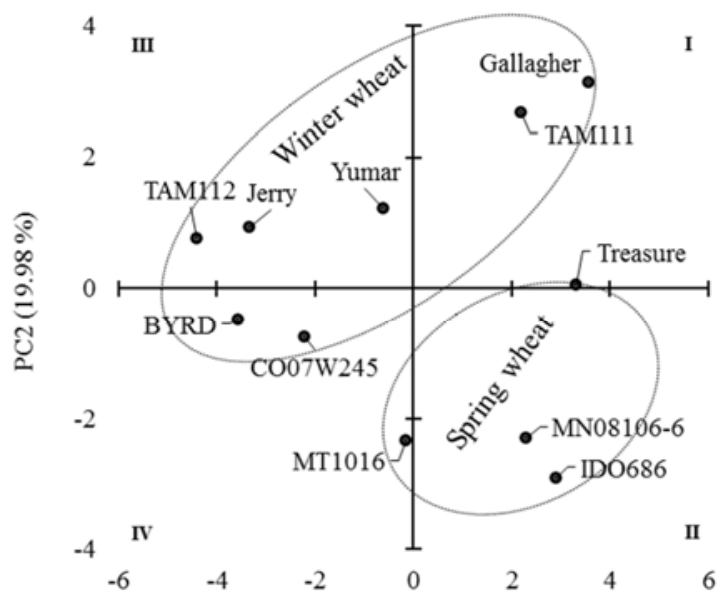

PC1 $(45.43 \%)$ 
655 Supplementary Fig. 1.

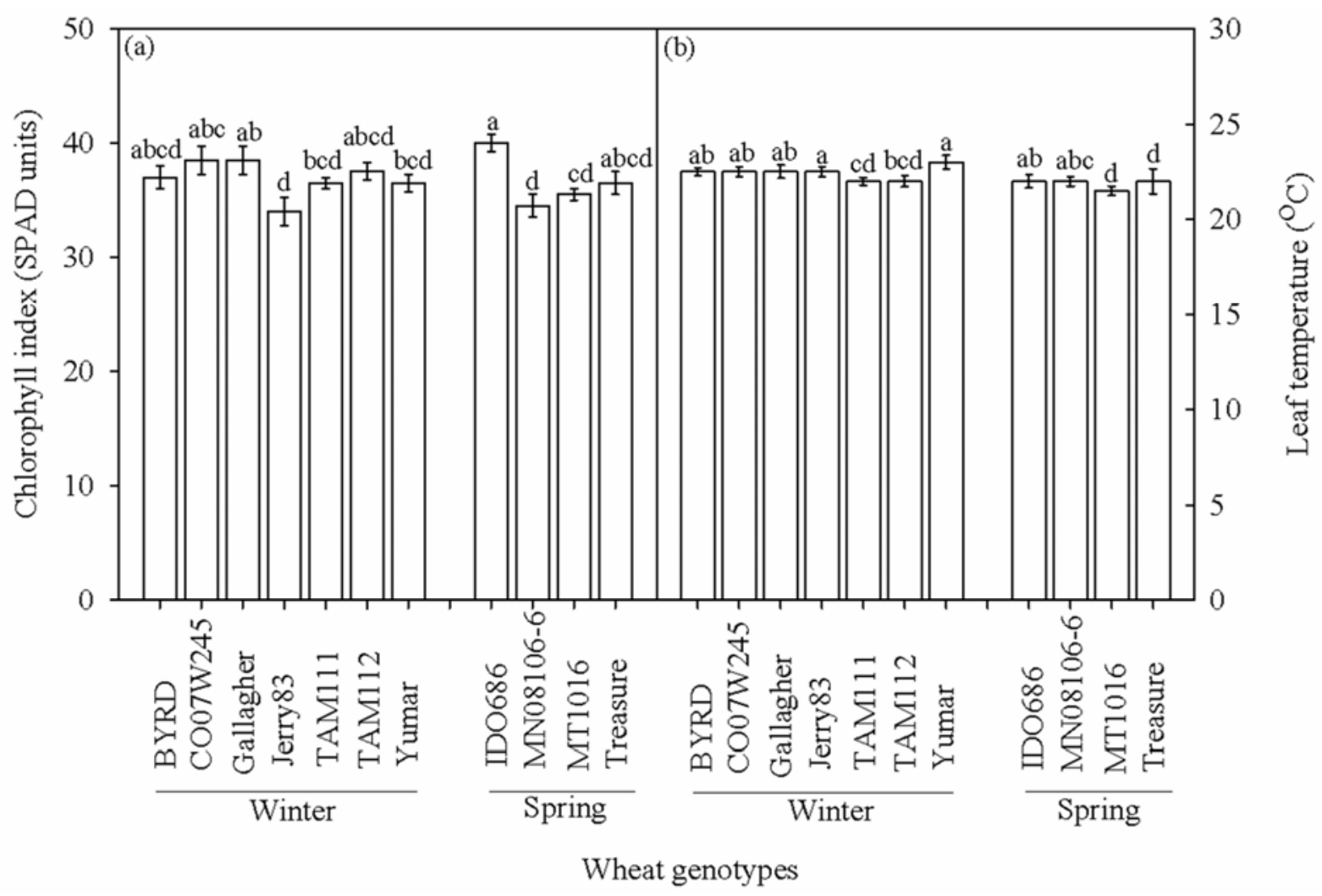

